\title{
GALATICAT, A NEW DITERPENE FROM SIDERITIS GALATICA SIDERÎTIS GALATICA 'DAN YENİ BİR DİTERPEN: GALATİCAT
}

\section{Ali DİŞLİ, Yılmaz YILDIRIR*，Ahmet YAŞAR}

Department of Chemistry, Faculty of Arts and Sciences, Gazi University, 06500, Teknikokullar, Ankara, TURKEY

\section{ÖZET}

Sideritis galalica adlı bitkinin toprak üstü klsımlarından petrol eteri ekstraksiyonu ile yeni bir diterpen-lakton izole edildi, spektroskopik yöntemlerle (FT-IR, $\left.1 \mathrm{H} \mathrm{NMR},{ }^{13} \mathrm{C} N M R, A P T, G C-M S\right)$ yapisl aydınlatılarak galaticat adı verildi.

\begin{abstract}
Galaticat, a new lacton-diterpene, has been isolated from the petroleum ether extract of aerial parts of Sideritis galatica. Its structure has been identified by spectroscopy $\left(F T-I R,{ }^{1} H \mathrm{NMR},{ }^{13} \mathrm{C} N M R\right.$, $A P T, G C-M S)$.

Key Word: Sideritis galatica; galaticat; lacton-diterpene; ent-15,16,17,20- tetra-nor-5,9-dihidroksi-6,19lacton labda-11-en
\end{abstract}

\section{INTRODUCTION}

Sideritis galatica is an endemic species growing in Kazan (Ankara, Turkey)(1). Sideritis species are used in Mediterranean traditional medicine for their antiinflammatory $(2,3)$, antimicrobial activity(2). The genus Sideritis is reported to contain diterpens(4-8), terpenoids(9), sterols(4), flavonoids, coumarins, lignins, iridoids and phenolic constituents(2).

\section{EXPERIMENTAL}

The melting point was determined in sealed capillaries and is uncorrected. FT-IR spectra were recorded on a Matson 1000 spectrometer. ${ }^{1} \mathrm{H}$ NMR and ${ }^{13} \mathrm{C}$ APT spectra were obtained with a Varian Gemini $200(200 \mathrm{MHz})$ NMR spectrometer using $\mathrm{CDC1}_{3}$ as a solvent unless otherwise indicated. All chemical shifts are reported ppm downfield from internal tetramethylsilane. Electron impact mass spectrometry at an ionization potential of $70 \mathrm{eV}$ was performed with a Micro MASS UK Platform GC-MS. 
Plant Material: Sideritis galatica was collected from Kazan region of Turkey in August 1996. The specimen is identified in Herbarium of the Biology Department, Gazi University.

Isolation of Diterpene: Dried and finely divided plants (1.60 $\mathrm{kg} S$. galatica), were Soxhlet extracted with petroleum ether (b.p. $40-60{ }^{\circ} \mathrm{C}$ ) in $72 \mathrm{hr}$. The petroleum ether extract was concentrated to $700 \mathrm{~mL}$ and then extracted $(4 \times 500 \mathrm{~mL})$ with $90 \%$ aqueous $\mathrm{MeOH}$. The methanolic extract was collected and concentrated to $500 \mathrm{~mL}$ by rotary evaporator. Then, total volume was diluted with water to $2000 \mathrm{~mL}$. This solution was extracted with chloroform $(8 \times 250$ $\mathrm{mL}$ ) and chloroform extracts were collected and evaporated until dryness(8). The oily residue was obtained in the flask.

The oily residue was dissolved in chloroform and purified by column chromatography (eluant $\mathrm{CHCl}_{3}: \mathrm{MeOH}$ 9:1). The similar fractions were collected. Four different extracts were collected from the column. Because of the amounts were too small, three of them couldn't purified. The latter was purified by thin layer chromatography (development solution, $\mathrm{CHCl}_{3}: \mathrm{MeOH} 9: 1$; stationary phase, silica gell $\left.60 \mathrm{PF}_{254+366}\right)$. The obtained product was crystallized from acetone (mp:66-67 $\left.{ }^{\circ} \mathrm{C}\right)$.

\section{RESULTS AND DISCUSSION}

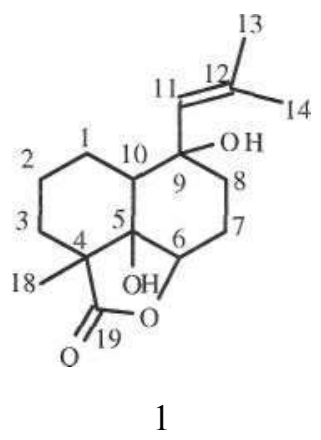

Galaticat (1), mp 66-67 ${ }^{\circ} \mathrm{C}, \mathrm{C}_{16} \mathrm{H}_{24} \mathrm{O}_{4}$ (mass spectra, $m / z$ : [M] 280). Its IR spectrum (Figure 1) showed characteristic absorptions for a carbonyl function at $1735 \mathrm{~cm}^{-1}$, a carbon-carbon double bond at $1635 \mathrm{~cm}^{-1}$, vinylic carbon-hydrogen bond stretching at $3043 \mathrm{~cm}^{-1}$. The ${ }^{1} \mathrm{H}$ NMR spectrum of galaticat, 1, (Figure 2) showed three methyl groups at approximately $\delta 0.9 \mathrm{ppm}$ (sbroad, 9H); a vinylic proton (on C-1 1) at $7.35 \mathrm{ppm}$ as singlet (it shifted to down field because of influence of $\mathrm{C}-\mathrm{OH}$ group); proton on $\mathrm{C}-6$ at 4.05 as triplet; also protons on C-7 at $1.6 \mathrm{ppm}$ as multiplet, proton on C-10 2.29 at ppm as triplet. See also Table 1 for chemical shifts and peak 
multiplicities of compound $\mathbf{I}$.The ${ }^{13} \mathrm{C}$ APT spectrum of 1 (Figure 3) confirmed the proposed structure (see Table 2).

Table 1. Chemical shift data $(\delta, \mathrm{ppm})$ and peak multiplicities of protons of compound I

7.35 (s, 1H, on C-11); 5.10 (s, 1H, on C-9 OH); 4.05 (t, 1H, on C-6); 2.29 (t, 1H, on C-10); 2.04 (broad, $1 \mathrm{H}$, on $\mathrm{C}-5 \mathrm{OH}) ; 1.6$ (m, 4H, on C-7 and C-8); 1.2 (broad, 6H, onC-1, C-2 and C-3); 0.9 (broad :5, 9H, onC-13, C-14andC-18)

Table 2. APT' Spectral data of compound 1 (in CDCI3)

\begin{tabular}{cccccc}
\hline $\mathbf{c}$ & $\mathrm{APT}$ & $\delta(\mathrm{ppm})$ & $\mathrm{C}$ & $\mathrm{APT}$ & $\delta(\mathrm{ppm})$ \\
\hline 1 & $\mathrm{CH}_{2}$ & 36.4 & 9 & $\mathrm{C}$ & 114.0 \\
2 & $\mathrm{CH}_{2}$ & 24.6 & 10 & $\mathrm{CH}$ & 96.0 \\
3 & $\mathrm{CH}_{2}$ & 34.2 & 11 & $\mathrm{CH}$ & 137.0 \\
4 & $\mathrm{C}$ & 66.3 & 12 & $\mathrm{C}$ & 127.0 \\
5 & $\mathbf{c}$ & 79.3 & 13 & $\mathrm{CH}_{3}$ & 16.1 \\
6 & $\mathrm{CH}$ & 99.0 & 14 & $\mathrm{CH}$ & 16.1 \\
7 & $\mathrm{CH}_{2}$ & 31.3 & 18 & $\mathrm{CH}$ & 25.4 \\
8 & $\mathrm{CH}_{2}$ & 33.9 & 19 & $\mathrm{C}$ & 175.9 \\
\hline
\end{tabular}

For example , lacton carbonyl group at $175.9 \mathrm{ppm}(\mathrm{APT}-\mathrm{C})$; three methyl groups at 16.1 ppm, $16.1 \mathrm{ppm}, 25.4 \mathrm{ppm}\left(\mathrm{APT}-\mathrm{CH}_{3}\right)$ and carbon atoms bearing -OH group at $78 \mathrm{ppm}$ apparent in APT spectrum. Also, molecular ion peak was observed at $280 \mathrm{~m} / \mathrm{z}(\mathrm{M})$. All these results confirm the proposed structure. 


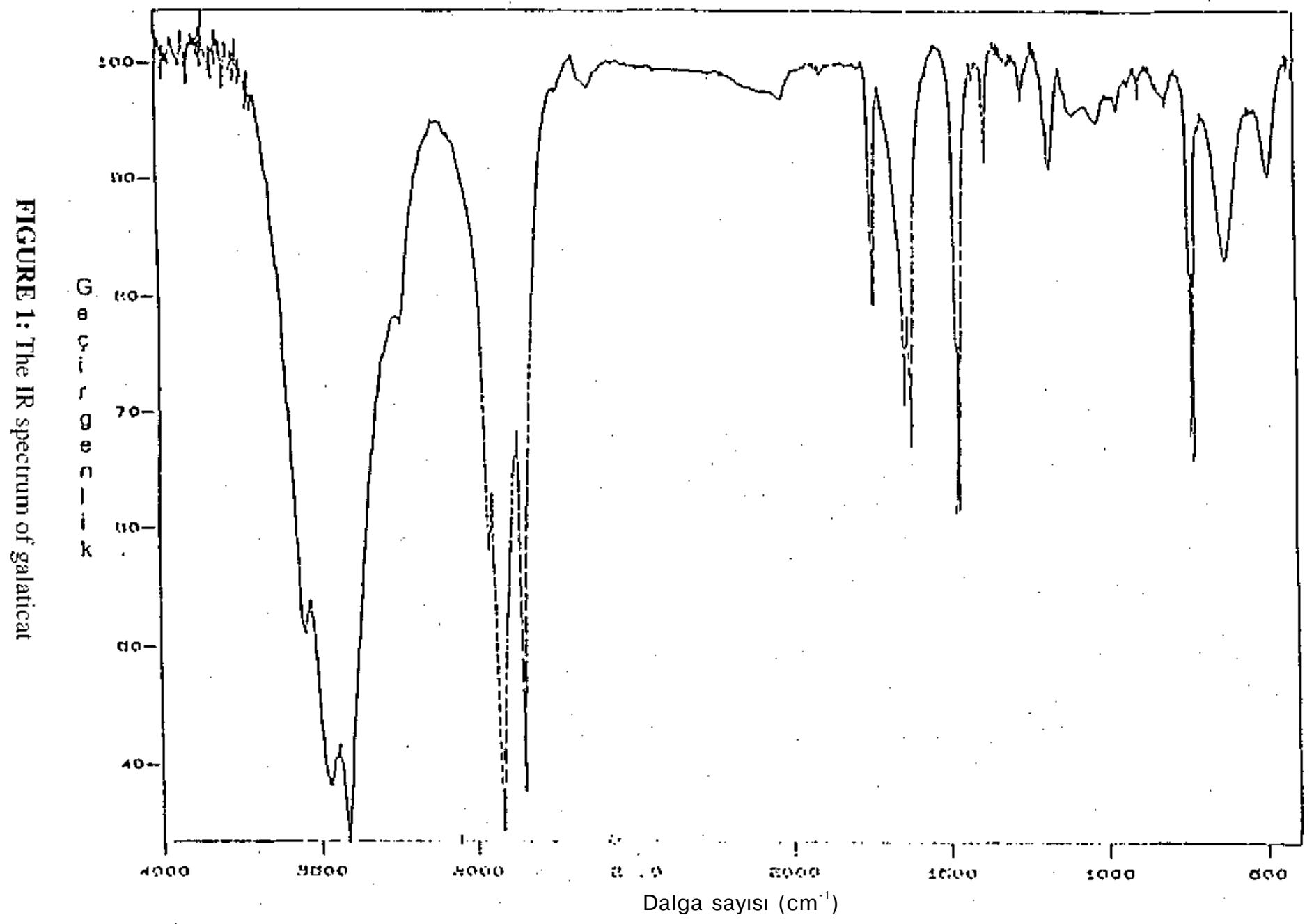

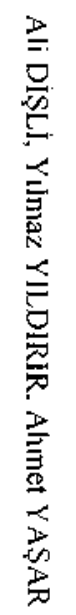




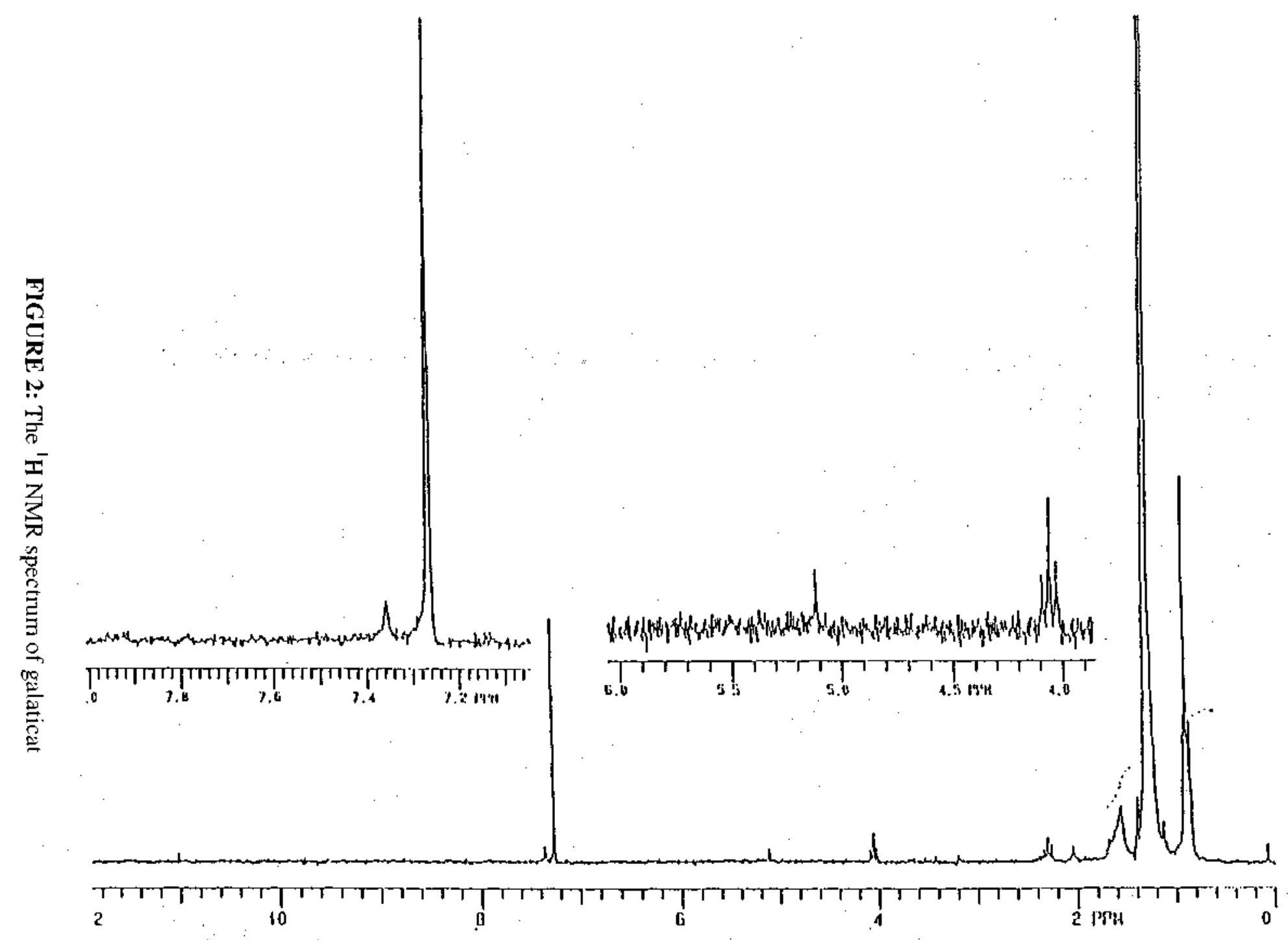


$\infty$

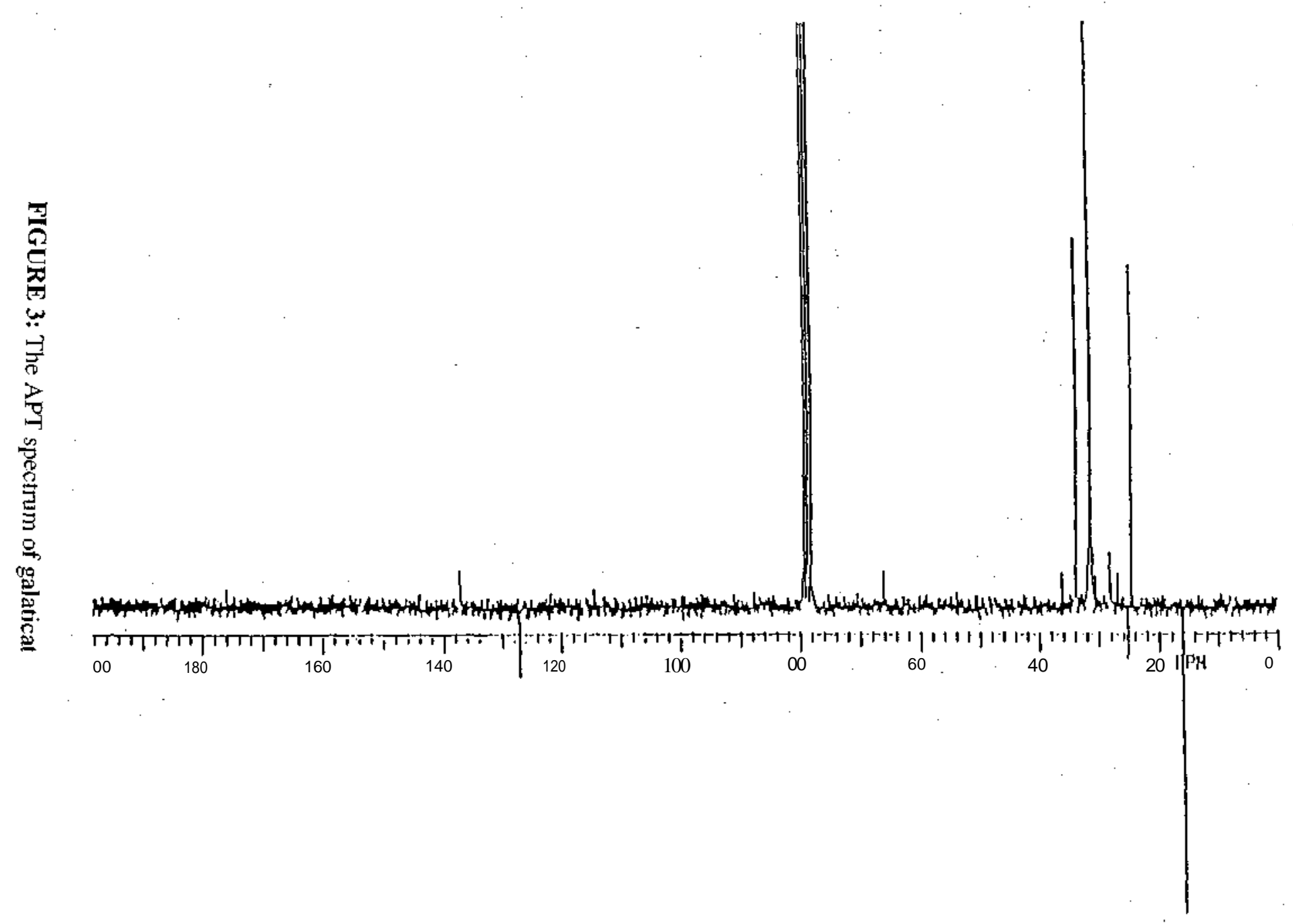

范 


\section{ACKNOWLEDGMENT}

We thank Dr. Zeki Aytaç (Department of Biology, Gazi University) for identification of the plant material and Gazi University Research Foundation for financial support.

\section{REFERENCES}

1- Davis, P. H., Mill, R. R. and Tan K., Flora of Turkey and The East Aegean Islands, Edinburgh, 7, p. 191 (1982)

2- Gabrieli, C. and Kokkalou, E. " Glucosylated Acylflavone from Sideritis Raeseri" Phytochemistry., 29, 681-683 (1990)

3- Rios, J. L., Manez, S., Paya, M. and Alcaraz, M. J. " Antioxidant activity of flavonoids from Sideritis Javalambrensis" Phytochemistry, 31, 1947-1950 (1992)

4- Algara, J., Garcia - Granados, A., Saenz De Buruaga, A. and Saenz De Buruaga, J. M. "Diterpenoids from Sideritis Varoi" Phytochemistry, 22, 1779-1782 (1983)

5- Fraga, B.M., Hernandez, M.G., Fernandez, C. and Arteaga, J.M. "Diterpenes from Sideritis Dendrochahorra and S. Cystosiphon" Phytochemistry, 26, 775-777 (1984)

6- Fraga, B. M., Hernandez, M.G., Santana, J. M. H. and Arteaga, J. M. ".Diterpenes from Sideritis Sventenii and 5. Cystosiphon" Phytochemistry, 29, 591-593 (1990)

7- Fraga, B. M., Guillerma, R., Hernandez, M. G., Mestres, T. and Arteaga, J. M. "Diterpenes from Sideritis Canariensis" Phytochemistry, 30, 3361-3364 (1991)

8- Venturella, P., Bellino, A. and Marino, M. L. "A diterpene from Sideritis Syriacd" Phytochemistry, 22, 2537-2538 (1983)

9- Rodriguez, B. and Valverde, S. "A new diterpenoid from Sideritis Mugrenensis, Barja(Labmtae)" Tetrahedron, 29, 2837-2843 (1973)

Bașvuru Tarihi: 07.01.2002

Kabul Tarihi: 09.05.2002 